\title{
Spatial and temporal variability of Arctic ice thickness
}

\author{
Gregory M. Flato \\ Canadian Centre for Climate Modelling and Analysis, Atmospheric Environment Service, University of Victoria, P.O. Box 1700, \\ MS 3339, Victoria, British Columbia V8W 212, Canada
}

\begin{abstract}
A numerical model is used to study the spatial and temporal variability of ice thickness in the Arctic. The model is run to cyclo-stationary equilibrium, forced with daily varying geostrophic winds and monthly varying surface air temperatures from 1951 to 1990 . Decadal-average winter ice-thickness fields exhibit a trend of increasing ice thickness in the East Siberian Sea and somewhat thicker ice overall in the $1980 \mathrm{~s}$. Inter-annual variability was largest in the Beaufort and East Siberian Seas and generally lower in the Laptev Sea and central Arctic. Spatial correlation patterns show that ice thickness at a point is correlated with ice thickness over a surrounding area of roughly $4 \times 10^{5} \mathrm{~km}^{2}$ with a correlation coefficient of 0.7. Temporal auto-correlation functions indicate that the total ice volume has a correlation time-scale of roughly 7 years, while the volume of ice between 2 and $5 \mathrm{~m}$ thick and the volume of ice less than $1 \mathrm{~m}$ thick have correlation times of roughly 2 years and 2 months, respectively.
\end{abstract}

\section{INTRODUCTION}

Global-climate-model studies have indicated high sensitivity of both ice extent and ice volume to $\mathrm{CO}_{2}$-induced warming, and so hinted at the possibility of early detection of climate change through monitoring of iceedge position and ice thickness (Parkinson, 1991). Indeed, Gloersen and Campbell (1991) found a small decrease in remotely sensed Arctic ice extent between 1978 and 1987, while Wadhams (1990) showed provocative evidence of a decrease in submarine-measured ice thickness north of Greenland between 1976 and 1987. On the other hand, McLaren and others (1992) compared mean thickness observed at the North Pole in the spring of six years between 1977 and 1990, and found large inter-annual variability with no significant trend. Finally, Chapman and others (1994) used a version of Hibler's (1979) "twolevel" sea-ice model, forced with observed inter-annually varying forcing from 1960 to 1988 , to illustrate the large inter-annual variability inherent in the Arctic ice cover, the persistence of ice-thickness anomalies and the ability of a model to reproduce the apparent decrease in thickness observed by Wadhams (1990) as part of the modelled inter-annual variability. Certainly a more systematic program to measure ice thickness would be valuable to establish ice thickness climatologies and variability against which to gauge future changes and to validate and improve sea-ice models.

In the present work we investigate sea-ice variability using a model which simulates the evolution of the entire thickness-distribution function, and forcing data which cover the period 1951-90. To the extent that the model is capable of reproducing the evolution of the real ice cover, this 39 year time series of ice thickness fields allows us to illustrate certain aspects of spatial and temporal variability relevant to monitoring Arctic ice thickness and ice volume.

\section{MODEL DESGRIPTION AND FORGING DATA}

The model used here is the same as that described by Flato and Hibler (in press), based on an earlier model of Hibler (1980), so it will be described only briefly. The ice thickness distribution, $g(h)$, is defined as (Thorndike and others, 1975)

$$
\int_{h_{1}}^{h_{2}} g(h) \mathrm{d} h=\frac{1}{R} r\left(h_{1}, h_{2}\right)
$$

where $h$ is ice thickness, $R$ is the total area of some fixed region, $\mathrm{R}$, about the point of interest, and $r\left(h_{1}, h_{2}\right)$ is the area in $\mathrm{R}$ covered by ice whose thickness is between $h_{1}$ and $h_{2}$. That is, $g(h)$ can be thought of as the normalized probability density function of ice thickness. This thickness-distribution function evolves according to (Thorndike and others, 1975)

$$
\frac{\partial g}{\partial t}=-\nabla \cdot(u g)-\frac{\partial}{\partial h}(f g)+\psi+F_{\mathrm{L}}
$$

where $u$ is the ice velocity, $f$ is the thermodynamic growth rate, $\psi$ is the so-called redistribution function, and $F_{\mathrm{L}}$ is a source term (added by Hibler (1980)) which describes the change in thickness distribution due to lateral melting. The redistribution term, $\psi$, a functional of $h$ and $g(h)$, determines the changes in $g(h)$ during a deformation event, essentially "redistributing" ice bet- 
ween thickness categories. The velocity field is obtained by solving the sea-ice momentum equation with the viscous-plastic, elliptical yield-curve rheology of Hibler (1979) and the strength parameterized in terms of mechanical energy losses during ridging (Rothrock, 1975). The total mechanical energy dissipation rate is taken to be 17 times the potential energy change as determined by Flato and Hibler (in press) from buoy-drift comparisons this value is similar to that determined by Hopkins (1994) from simulations of individual ridging events). The thickness distribution is represented by 28 fixed thickness categories, closely spaced near the thin end of the distribution and progressively coarser for thicker ice with separate distributions for ridged and level ice (Flato and Hibler, in press). The model includes snow accumulation on the ice, with average monthly snowfall rates obtained from the Russian ice-station data from 1957-61 reported in Vowinckel and Orvig (1970). The thermodynamic growth rate is obtained from a surface energybudget calculation essentially the same as that of Parkinson and Washington (1979), as described in Hibler (1980), and the Semtner (1976) "zero-layer" heat-conduction formulation. Further details can be found in Flato and Hibler (in press).

The model uses a $160 \mathrm{~km}$ rectangular grid, shown in Figure 1, and is forced with daily geostrophic winds constructed from surface pressure analyses archived at the U.S. National Center for Atmospheric Research, and augmented by Arctic Buoy Program pressure fields north of $70^{\circ} \mathrm{N}$ after 1979 (Chapman and others, 1994). Monthly surface air temperatures are from the University of East Anglia, U.K. (Jones and others, 1986), and consist of monthly temperature anomalies, where available, superimposed upon monthly climatology. Because the anomalies are derived from weather-station records, there are generally none available over the central Arctic and so the

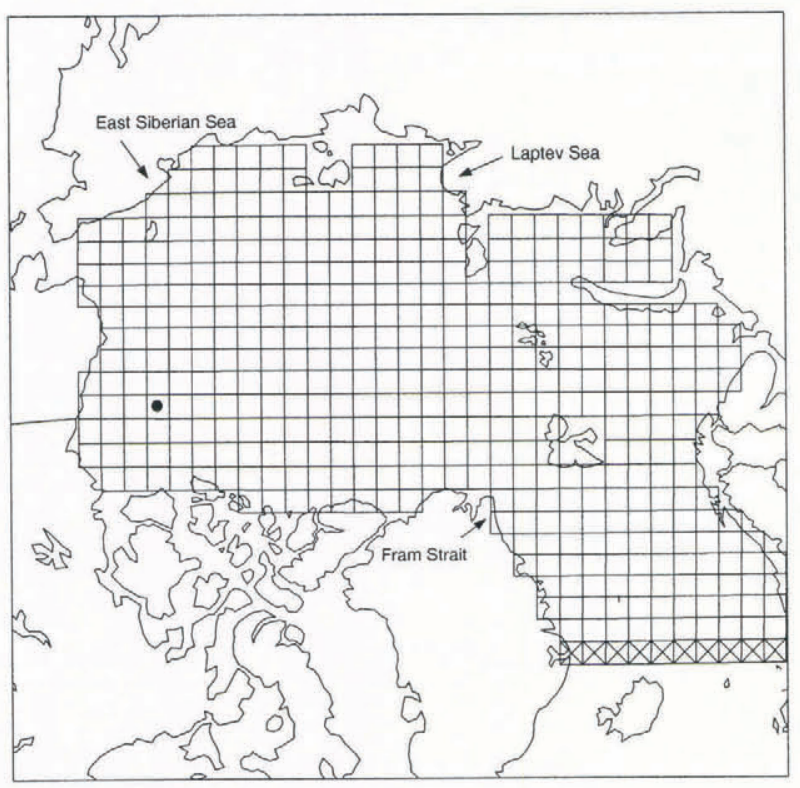

Fig. 1. Model grid. Each grid square is $160 \mathrm{~km}$ on a side. The cross-hatched grid cells indicate outflow boundary points through which ice is free to exit the model domain. The solid black dot indicates the location of the thicknessdistribution functions plotted in Figure 2.
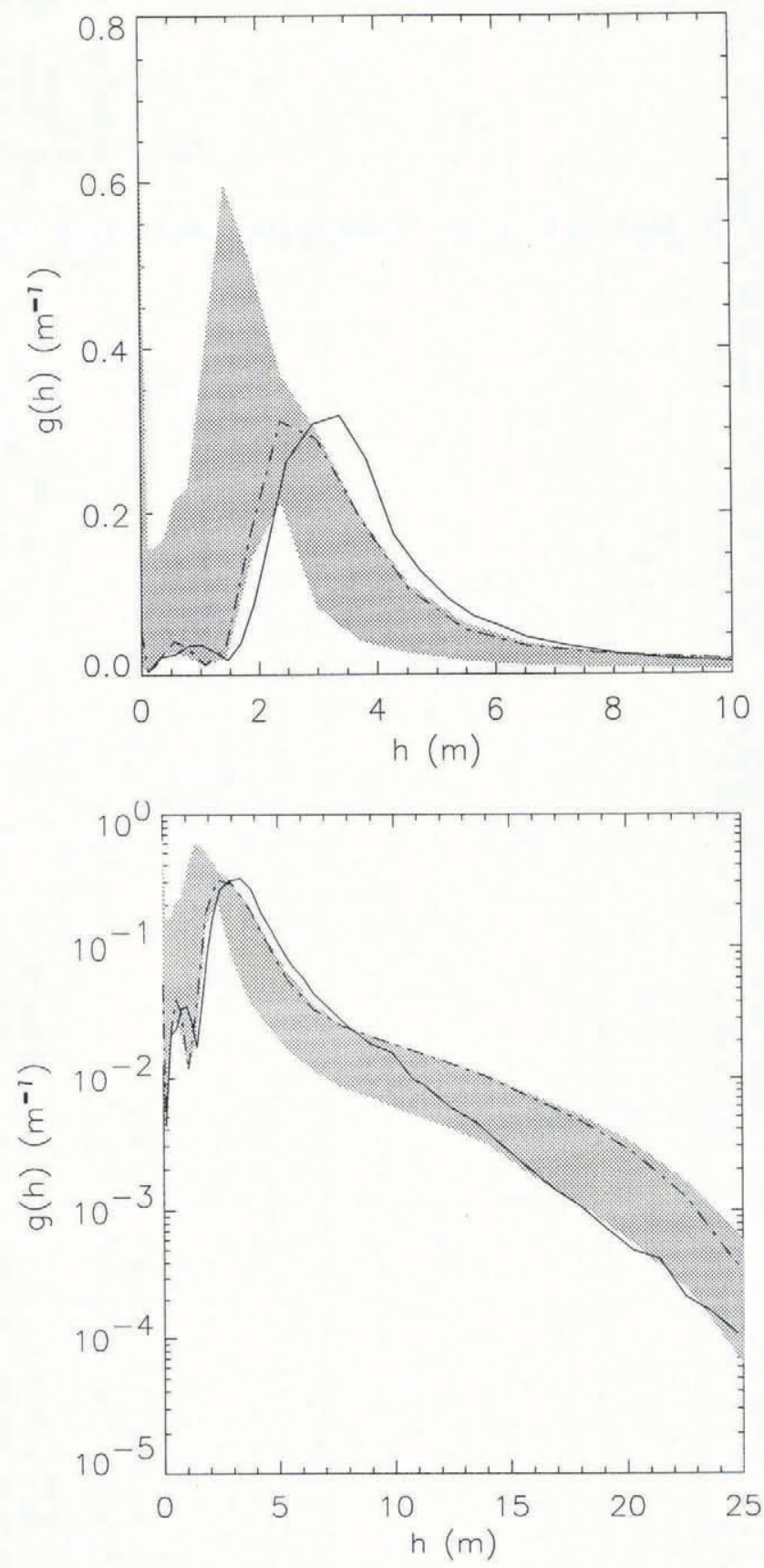

Fig. 2. Modelled and observed ice thickness distribution functions at the point indicated in Figure 1. The dashed line is the model result from April 1976; the solid line is an observed thickness distribution from April 1976; and the shaded area indicates the range in modelled thickness distributions for April over the period 1951-90. (a) Linear plot, (b) semi-logarithmic plot.

modelled ice cover experiences inter-annually varying air temperatures only near the coast. Furthermore, the binning procedure used to construct the anomaly data produces spurious warm temperatures over sea ice in the summer, causing unrealistic melt. Observations from Russian ice camps (e.g. Vowinckel and Orvig, 1970) show that air temperatures over sea ice rarely exceed the freezing point in summer (the maximum ice-surface temperature). Therefore the air temperatures are modified by not allowing temperatures greater than $0.5^{\circ} \mathrm{C}$ in grid cells where the ice concentration is greater than $15 \%$. Down-welling long-wave radiation is calculated from air 
temperature and cloud amount using the parameterization of Maykut and Church (1973); short-wave radiation is obtained from the Zillman (1972) clear-sky formulation along with the same cloud modification used by Chapman and others (1994). Monthly climatological cloud amounts are taken from Ebert and Curry (1993). Average monthly ocean-surface currents and heat fluxes are taken from the $40 \mathrm{~km}$ resolution coupled ice ocean simulation of Hibler and Zhang (1993).

\section{RESULTS OF 39 YEAR SIMULATION}

Thick, ridged ice evolves very slowly, owing to its long lifetime in the central Arctic, and so the distribution of ridged ice takes 10 years or more to reach equilibrium (Flato and Hibler, in press). Therefore, the model was initialized with a thickness-distribution field obtained from a previous simulation of the years 1979 -85, then run through the 1951-90 period once and the thicknessdistribution field from the end of this run used as an initial condition for the final 1951-90 simulation. The model is effectively in cyclo-stationary equilibrium, and only the results from the final 39 year simulation will be discussed. An example of the thickness distribution at a point in the Beaufort Sea for 30 April 1976 is shown in Figure 2 along with the range in distributions for all Aprils, 1951-90. Also shown for comparison is the thickness distribution observed by U.S.S. Gurnard in the Beaufort Sea during April 1976 (Wadhams and Horne, 1980). The general shape of the distribution is reproduced quite well by the model, including the bimodal structure reflecting firstyear and multi-year ice. The range in modelled distributions shows that inter-annual variability in the shape of the distribution function is confined to thin ice less than $3 \mathrm{~m}$ or so). The shape of the tail of the distribution remains essentially the same, with the mean thickness primarily reflecting the relative amounts of thin, level ice and thick, ridged ice.

In order to describe spatial variability, we now focus on the first moment of the thickness distribution, the mean thickness. Decadal averages of winter (JanuaryMarch) mean thickness fields are shown in Figure 3 and illustrate the substantial changes in thickness buildup pattern that occur, particularly the trend toward thicker ice in the East Siberian Sea. In all decades, the observed
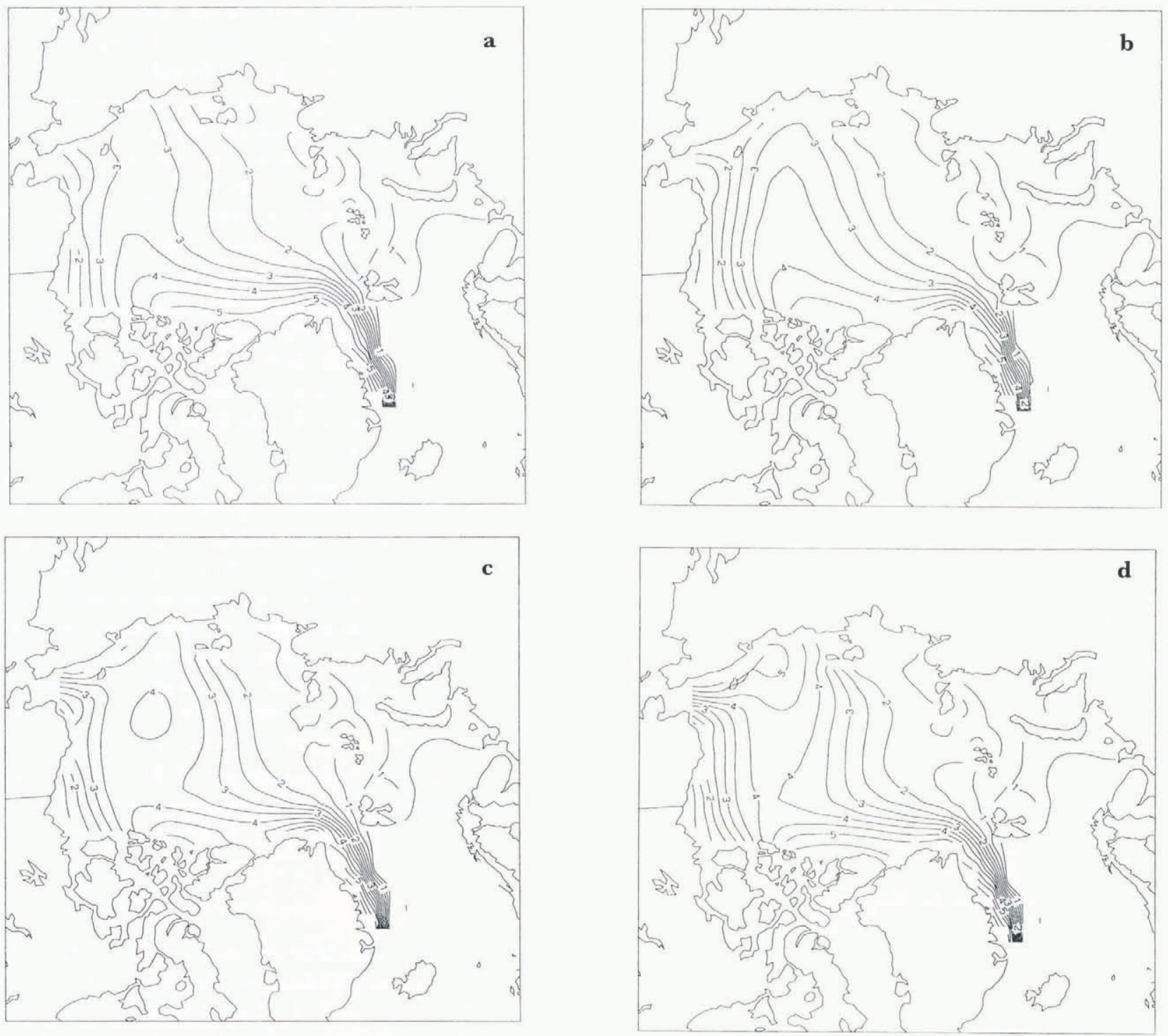

Fig. 3. Decadal-average winter (January-March) mean ice thickness fields. (a) 1950s, (b) 1960s, (c) 1970s, (d) $1980 \mathrm{~s}$. Contour interval is $0.5 \mathrm{~m}$. 
zone of thick ice along the Canadian Archipelago and north Greenland coast is reproduced, with the ice generally thicker during the 1980 s than during the earlier decades.

One way to monitor Arctic sea-ice volume would be to deploy a network of fixed sensors which measure the ice thickness at their location. The design of such a network would of course aim to measure the maximum signal with the fewest sensors. The placement of measurement sites in such a network depends on the goal of the measurement program. If one was interested in observing inter-annual and short-term variability, the strategy would presumably be to place monitoring sites in regions which exhibit the largest fraction of the overall variability. On the other hand, if one was interested in observing long-term trends in the ice volume, monitoring sites would likely be placed at low-variability sites to reduce the background "noise level" in the observations. To give an idea of where such regions are, Figure 4 shows the variance of February and August ice thicknesses (that is, at each point we compute the variance of the 39 February or August mean thicknesses). The East Siberian Sea again appears as a region of large inter-annual variability. Indeed when one
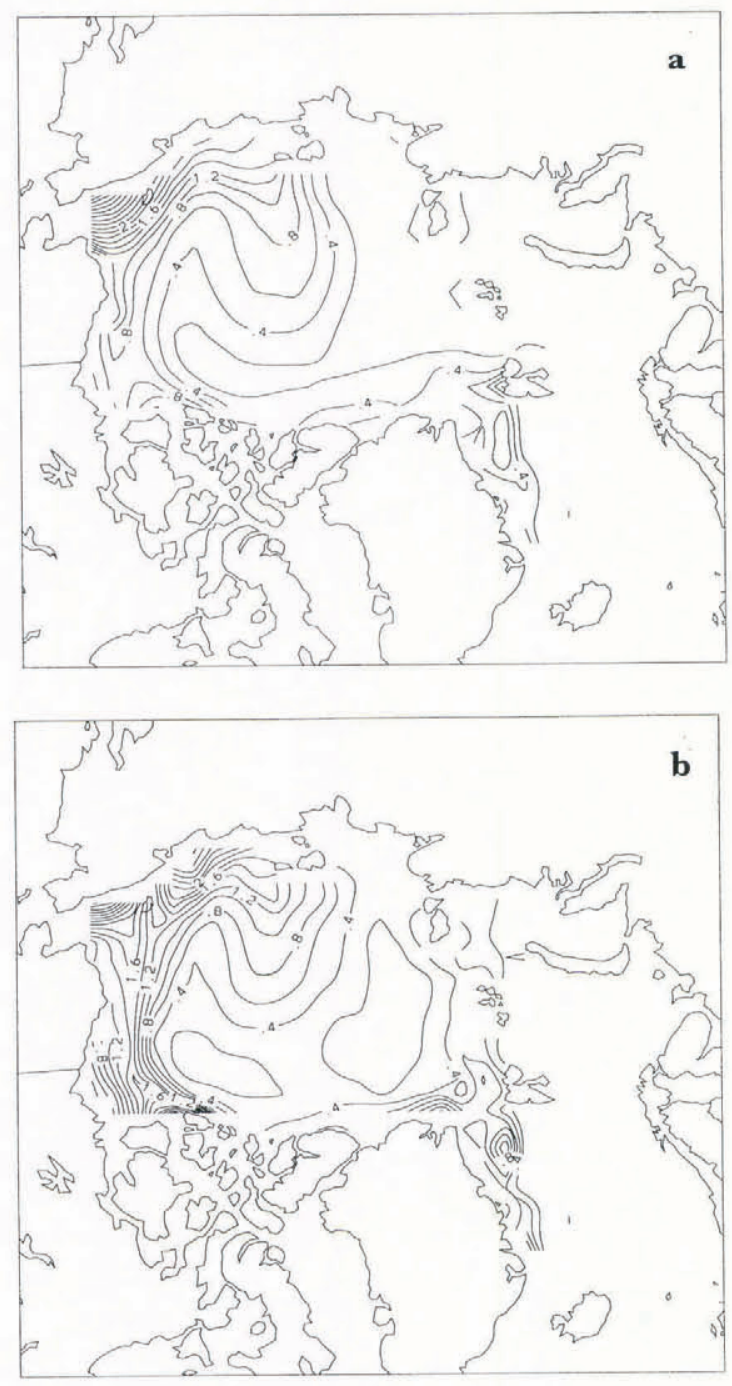

Fig. 4. Variance of February and August mean ice thickness over the period 1951-90. (a) February, (b) August. Contour interval is $0.2 \mathrm{~m}^{2}$. considers the dominant circulation pattern, an anticyclonic gyre in the western Arctic, it appears that highvariability ice is advected off the Siberian Shelf while lowvariability ice from the central Arctic is advected into this region.

Optimal spacing of sites within a monitoring network depends on the correlation structure of the thickness field. The correlation is estimated as

$$
\rho\left(x_{1}, y_{1}, x_{2}, y_{2}\right)=\frac{\operatorname{Cov}\left(x_{1}, y_{1}, x_{2}, y_{2}\right)}{\sigma\left(x_{1}, y_{1}\right) \sigma\left(x_{2}, y_{2}\right)}
$$

where

$$
\begin{aligned}
& \operatorname{Cov}\left(x_{1}, y_{1}, x_{2}, y_{2}\right)=\frac{1}{12 N_{\mathrm{yr}}} \sum_{k_{\mathrm{yr}}=1}^{N_{\mathrm{yr}}} \sum_{k_{\mathrm{mmon}}=1}^{12} \\
& \left(\bar{h}_{k}\left(x_{1}, y_{1}\right)-\left\langle\bar{h}\left(x_{1}, y_{1}\right)\right\rangle_{k_{\text {mon }}}\right)\left(\bar{h}_{k}\left(x_{2}, y_{2}\right)-\left\langle\bar{h}\left(x_{2}, y_{2}\right)\right\rangle_{k_{\text {mon }}}\right)
\end{aligned}
$$

and

$$
\sigma(x, y)=\sqrt{\operatorname{Cov}(x, y, x, y)} ; k=k_{\mathrm{mon}}+12\left(k_{\mathrm{yr}}-1\right) ; \bar{h}_{k}(x, y)
$$

is the mean thickness at point $(x, y)$ averaged over month $k$ counted from January 1951; $N_{\mathrm{yr}}=39$ is the number of years; and \langle\rangle$_{k_{\text {mon }}}$ indicates the average of month $k_{\text {mon }}$ over the $N_{\mathrm{yr}}$ period $\left(k_{\mathrm{mon}}=1\right.$ is January, $k_{\mathrm{mon}}=2$ is February, etc.). We have implicitly assumed that the correlation is stationary. The model-derived correlation field, $\rho(x, y, \tilde{x}, \tilde{y})$, is shown in Figure 5 for several points $(\tilde{x}, \tilde{y})$, where $(\tilde{x}, \tilde{y})$ are denoted by the heavy black dots in the figure. The area enclosed by the $\rho=0.7$ contour (within which a local measurement ${ }^{1}$ explains about $50 \%$ of the variance of the surrounding ice) is generally about $4 \times 10^{5} \mathrm{~km}^{2}$. As a crude estimate, take this as the area represented by a local measurement; it would therefore take roughly 20 measurement sites to monitor Arctic ice volume. In estimating the total Arctic ice volume, one would not weight all these sites equally; rather, the weights would be assigned based on the variance covariance structure of the thickness field through some optimization procedure.

Given the correlation structure estimated by the model, one could design an optimal measurement network and estimate the measurement error. However, one might also ask about the temporal variability in the ice volume that would be observed by such a network, and so we will examine briefly the ice-volume time series produced by the model. Figure 6 shows the time series of total ice volume and "thin" ice volume defined as the volume of ice whose thickness is less than $1 \mathrm{~m}$ ) in the model domain over the 39 year simulation. Also shown is the anomaly time series constructed by subtracting the average annual cycle. Since the model is forced to be in cyclo-stationary equilibrium, there is no overall trend

\footnotetext{
1 By a "local" measurement we mean an estimate of the mean thickness obtained by sampling an area large enough or a transect long enough to provide a meaningful estimate of the mean; a $100 \mathrm{~km}$ transect would be typical (see, e.g., Rothrock (1986) for a more comprehensive discussion).
} 

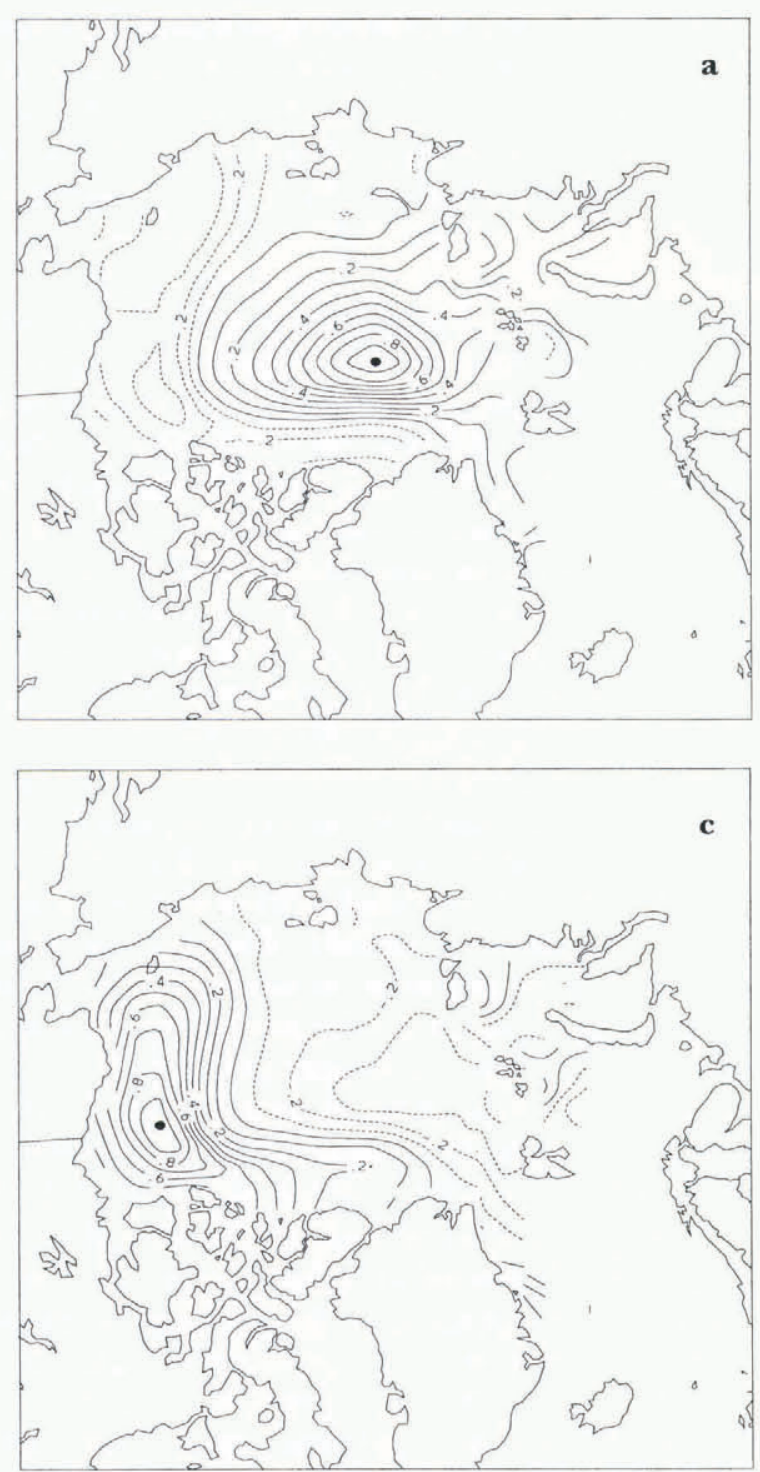
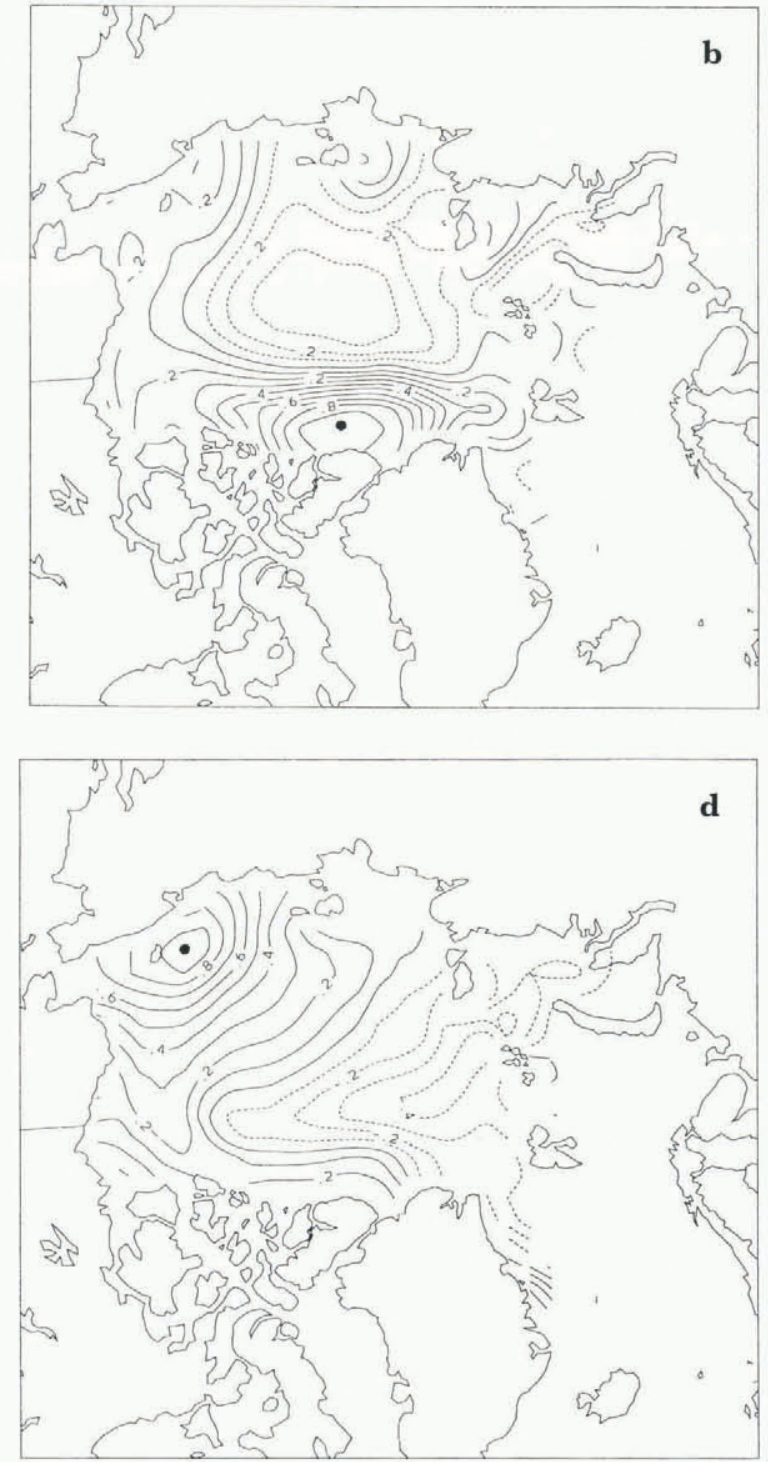

Fig. 5. Correlation of mean ice thickness relative to that at the point indicaled by a heavy black dot. Contour interval is 0.1.

(the volume at the beginning of 1951 is the same as the volume at the end of 1990); however, there is a change in the mid-1970s from "below-average" to "above-average" total ice volume. How much of this is due to the introduction, in 1979, of Arctic buoy data into the surface pressure fields used to force the model is unknown.

The temporal auto-correlation function (ACF) of icevolume anomaly is shown in Figure 7 for total and thin ice as well as for "medium" thickness ice (defined as thickness of 2-5 m). One can estimate a correlation timescale by fitting an exponential to the initial decaying part of each ACF recall that the ACF of a first-order autoregressive process ${ }^{2}$ is an exponential function; e.g. Jenkins and Watts, 1968). This yields time-scales of approxi-

\footnotetext{
${ }^{2}$ Power spectra of these time series (not shown) indicate that a first-order auto-regressive, "red-noise" process is a reasonably good approximation. The time-scales estimated in this way are very similar to those one would obtain from the lag at which the ACF first becomes indistinguishable from zero.
}
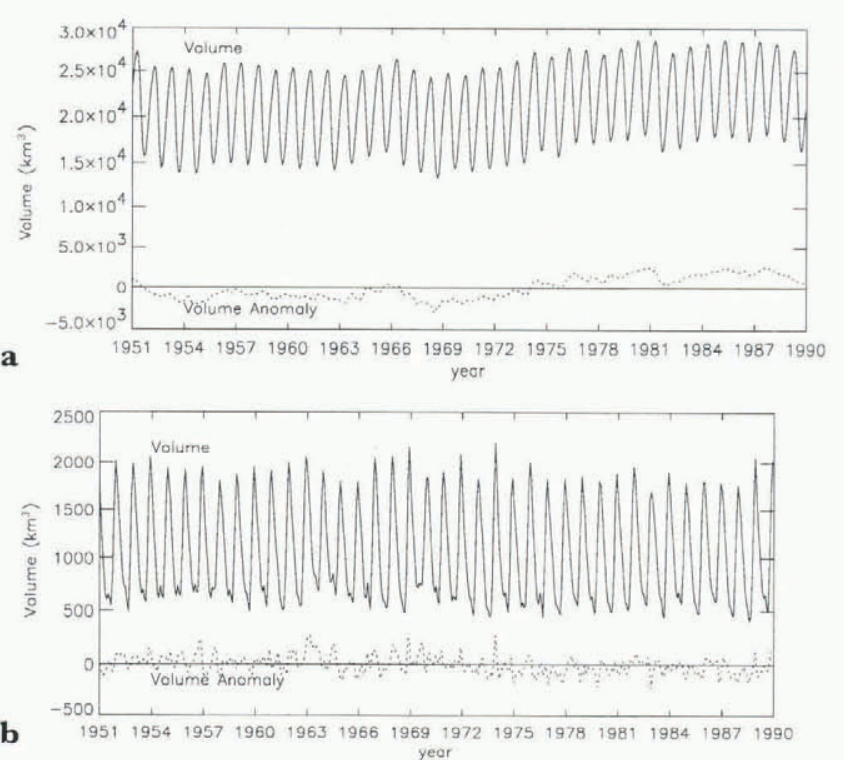

Fig. 6. (a) Time series of total ice volume in the model domain (solid line) and volume anomaly (dashed line) computed by subtracting the average annual cycle from the volume time series. (b) Thin-ice $(<I m)$ volume and volume-anomaly time series. 


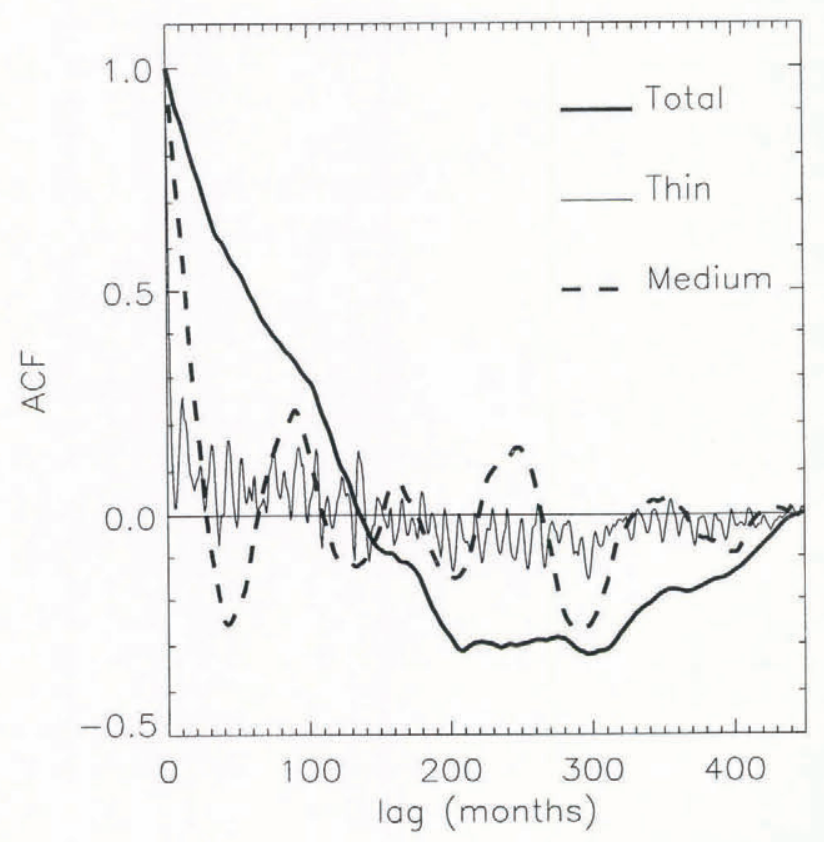

Fig. 7. Auto-correlation functions of total, medium$(2 m \leq h \leq 5 m)$ and thin-ice $(h \leq 1 \mathrm{~m})$ volume-anomaly time series.

mately 7 years for total ice volume, 20 months for medium-ice volume and 2 months for thin ice volume. The short time-scale associated with thin ice variability reflects the fact that such ice is primarily formed by freezing of open water in newly exposed leads and is subsequently destroyed by ridging; both events coincide with the passage of synoptic systems across the Arctic. Thin ice, however, accounts for only about $5 \%$ of the total volume, and so the overall behavior is dominated by thicker ice. Ice thicker than $5 \mathrm{~m}$ is formed almost exclusively by ridging, and accounts on average for just under half of the total ice volume. Once formed, such ice can survive the summer melt and remain in the central Arctic for many years before exiting through Fram Strait. Roughly $10-20 \%$ of the total Arctic ice volume is transported through Fram Strait each year, implying a renewal time of 5-10 years. A several-year time-scale is also expected from the slow evolution of ridged ice volume noted by Flato and Hibler (in press).

\section{DISCUSSION AND CONCLUSIONS}

Sea-ice extent and volume represent observable measures of the climatic state in the polar regions. Ice extent has been routinely monitored by satellite imagery for about 20 years; however, ice volume would be a more useful quantity to monitor since it is directly related to heat and fresh-water storage. The technology to observe ice thickness (volume per unit area) using moored upwardlooking sonar devices is available and motivates the analysis of modelled ice thickness performed here. Using a fairly comprehensive sea-ice model forced with daily varying winds and monthly mean air temperatures from 1951 to 1990 , we computed monthly-average ice thickness fields over the Arctic Ocean and peripheral seas and examined aspects of the spatial and temporal variability.
Regions exhibiting the largest inter-annual variability were the Beaufort Sea and the Siberian Shelf. The Laptev Sea and central Arctic were much less variable. Interestingly, Flato and Hibler (in press) found that the Beaufort Sea and Siberian Shelf areas experienced substantially more ridging than the Laptev Sea or central Arctic, and so much of the inter-annual variability may result from differences in wind-driven ridging, forming thick ice which survives several years. The spatial correlation fields showed areas, surrounding a point, of about $4 \times 10^{5} \mathrm{~km}^{2}$ in which the correlation coefficient was above 0.7 . This sort of information could be used in the design of an ice-thickness monitoring network. Insofar as the modelled ice volume time series are representative of the real Arctic, we would anticipate a temporal correlation time-scale of roughly 7 years for total ice volume, 2 years for the volume of ice between 2 and $5 \mathrm{~m}$ thick and 2 months for the volume of ice less than $1 \mathrm{~m}$ thick. Particularly for total ice volume, this serial correlation must be taken into account in statistical tests aimed at detecting a trend (see, e.g., Laurmann and Gates (1977) for a more complete discussion of the issues involved) and make it unlikely that ice volume will provide an "early" indication of climate change. Detection of trends in ice-covered areas may be more feasible in this regard, since the correlation time-scale of ice-area anomalies is only about 3 months, a time-scale associated with heat storage in the marginal ice-zone mixed layer (Lemke and others, 1980). That is not to say that one should neglect systematic ice thickness monitoring. Indeed, measurement of ice thickness (in fact, the ice thickness distribution function) is vital for the validation of sea-ice models used in global climate simulations, in terms of their ability to reproduce both observed climatological thickness patterns and realistic interannual variability.

\section{ACKNOWLEDGEMENTS}

I am grateful to F. Zwiers for many helpful discussions on statistics. I thank W. Chapman for kindly providing the surface-pressure and air-temperature data and B. van Hardenberg for writing programs to interpolate data to the model grid. F. Zwiers, J. Cherniawsky, D. Rothrock and an anonymous reviewer provided valuable comments on the draft manuscript.

\section{REFERENCES}

Chapman, W. L., W.J. Welch, K. P. Bowman, J. Sacks and J. E. Walsh. 1994. Arctic sea ice variability: model sensitivities and a multidecadal simulation. J. Geophys. Res., 99 (C1), 919-935.

Ebert, E. E. and J. A. Curry. 1993. An intermediate one-dimensional thermodynamic sea ice model for investigating ice-atmosphere interactions. f. Geophys. Res., 98 (C6), 10,085-10,109.

Flato, G. M. and W.D. Hibler, III. In press. Ridging and strength in modelling the thickness distribution of Arctic sea ice. j. Geophys. Res.

Gloersen, P. and W.J. Campbell. 1991. Recent variations in Arctic and Antarctic sea-ice covers. Nalure, 352 6330), 33-36.

Hibler, W. D., III. 1979. A dynamic thermodynamic sea ice model. 7 . Pliys. Oceanogr., 9 4), 815-846.

Hibler, W.D., III. 1980. Modeling a variable thickness sea ice cover. Mon. Weather Rev., 108 12), 1943-1973.

Hibler, W.D., III and J. Zhang. 1993. Interannual and climatic 
characteristics of an ice ocean circulation model. In Peltier, W. R., ed. lce in the climate system. Berlin, etc., Springer-Verlag, 633-651.

Jones. P. D., S. C. B. Raper, R. S. Bradley, H. F. Diaz, P. M. Kelly and T. M. L. Wigley. 1986. Northern Hemisphere surface air temperature variations, 1851-1984. J. Climate Appl. Meteorol., 25, 161-179.

Laumann, J. A. and W. L. Gates, 1977. Statistical considerations in the evaluation of climatic experiments with atmospheric general circulation models. F. Atmos, Sci., 34, 1187-1199.

Lemke, P., E. W. Trinkl and K. Hasselmann. 1980. Stochastic dynamic analysis of polar sea ice variability. J. Phys. Oceanogr., 10 (12), 21002120.

McLaren, A.S., J. E. Walsh, R.H. Bourke, R. L. Weaver and W. Wittmann. 1992. Variability in sea-ice thickness over the North Pole from 1977 to 1990. Nature, 358 6383), 224-226.

Maykut, G. A. and P.E. Church. 1973. Radiation climate of Barrow, Alaska, 1962 66. J. Appl. Meteorol., 12 4), 620-628.

Parkinson, C. L. 1991. Strengths and weaknesses of sea ice as a potential early indicator of climate change. In Weller, G., C. L. Wilson and B.A. B. Severin, eds. International Conference on the Role of the Polar Regions in Glabal Change. Proceedings of a Conference held June 11 1.5, 1990 at the University of Alaska Fairbanks. Vol. I. Fairbanks, AK, University of Alaska, 17-21.

Parkinson, C. L. and W. M. Washington. 1979. A large-scale numerical model of sea ice. 7. Geophys. Res., 84 C1) $311-337$.

Rothrock, D. A. 1975. The energetics of plastic deformation of pack ice by ridging. J. Geophys. Res., 80 33, 4514 4519.

Semtner, A.J., Jr. 1976. A model for the thermodynamic growth of sea ice in numerical investigations of climate. f. Phys. Oceanogr., 6 3), 379-389.

Thorndike, A. S., D. A. Rothrock, G. A. Maykut and R. Colony. 1975. The thickness distribution of sea ice. J. Geophys, Res., 80 33), 45014513.

Vowinckel, E. and S. Orvig. 1970. The climate of the north polar basin. In Orvig, S., ed. Climates of the polar regions. Amsterdam, etc., Elsevier, 129-252. World Survey of Climatology, Vol. 14.

Wadhams, P. 1990. Evidence for thinning of the Arctic ice cover north of Greenland. Nature, 3456278 , 795-797.

Wadhams, P. and R.J. Horne. 1980. An analysis of ice profiles obtained by submarine sonar in the Beaufort Sea. F. Glaciol., 25 93), 401-424.

Zillman, J. W. 1972. A study of some aspects of the radiation and heat budgets of the Southern Hemisphere oceans. Canberra, Department of the Interior. Bureau of Meteorology. (Meteorological Studies 26. 